\title{
What Service?
}

\author{
Ana Cardoso $^{1}$, Isabel Ferreira ${ }^{1}$, João Álvaro Carvalho ${ }^{1,2}$, Leonel Santos ${ }^{1,2}$ \\ ${ }^{1}$ Centro Algoritmi, ${ }^{2}$ Information Systems Department of University of Minho \\ Universidade do Minho, Campus de Azúrem, 4800-058 Guimarães \\ \{anachcardoso, iferreiragisa\}@gmail.com, \{jac, leonel\}@dsi.uminho.pt
}

\begin{abstract}
Technology is changing society, organizations, and interactions between service organizations and customers at a fast pace. Moreover, technology is transforming the nature of services and, in academia, multidisciplinary research is trying to make sense of these changes and leverage the opportunity of service innovation in different fields. After a brief review of the literature focused on services, we found that the term "service" is often used to mean many different things. This paper explores the meaning and scope of services in technological and managerial domains. As a final result, we summarize the concepts of services in the broad areas of management and technology that we found in the literature. Management refers to the concepts that are often used in the fields of marketing and operations management, whereas technology includes the service-like concepts from the fields of software engineering and information systems.
\end{abstract}

Keywords: services, service science, service concept, and taxonomy

\section{Introduction}

In recent past, there has been a renewed interest in the concept of service. In different areas, such as marketing, operations management (OM), software engineering (SE) and information systems (IS), the term "service" is used to refer to different things. For example, in marketing, services refer to the provision of intangible goods that are valued and traded in the market. In SE this term usually nominates an abstraction useful for implementing software applications for open environments in a productive and scalable manner [1]. In IS we can find the word in different contexts, either to refer to electronic or digital services or to the infrastructure layer of organizations that provides the computing capabilities that help organizations achieving their goals.

Many agree that services have been at the core of economic activity in the past years $[2,3,4,5]$. There seems to be a relation between the dominance of services in world economy and the growing phenomenon of outsourcing. Information technology (IT) and Internet facilitate the creation of a commoditization-logic of services and knowledge work, as for example payroll transactions, programming, and help desk services, that are increasingly being outsourced [6]. Despite the economic stagnation of the last years and the growing unemployment in many industries, there has been a 
growing demand for labor in the sector of services, in both developed and developing countries, thus confirming this outsourcing trend [7,8].

Researchers in the aforementioned disciplines have been refocusing their interests in services, given the complex transformations occurring in society and the belief that the future of global economy is deeply related to growth in the services sector [9]. The recognition of the growing importance of services in today's world and the interdisciplinary and complex nature of today's services led to the emergence of a new discipline - Service Science Management and Engineering (SSME) [4]. This new discipline intends to tackle emergent service research problems with interdisciplinary approaches and is expected to grow as a meeting place and forum for discussion of service related problems, regardless the original field of study of researchers and practitioners.

The multiple uses of the term "service" in different disciplines sometimes introduces confusion. Therefore, a clarification is needed. Services as a general category of products that involve deeds, acts or performances [10] - a classical and well-known definition from $\mathrm{OM}$ and marketing - does not reflect anymore the complete set of possible entities or situations currently presented as services. The distinction among different types of services, can lead to multiple perspectives, each with its own narrow focus, such as IT-enabled services or electronic services, services infrastructure of organizations, or service-oriented design of software. Such line of development is contrary to what is being suggested by the proposers of SSME that aim at an interdisciplinary and integrative approach to the study, management and engineering of services.

This paper is organized as follows. Section 2 is a discussion of literature with focus on the services concept in different areas. Section 3 presents examples of services taxonomies found in the literature. Conclusions and future work are discussed in Section 4.

\section{A Review of the Concept of Services}

The usage of the word "service" by different disciplines is often confusing because of the multitude of meanings that are involved. Even when the word is used in the context of a single discipline, ambiguity still persists. For example, in management literature, there is inherent ambiguity with the concept of services because it can mean, "an industry, an output or offering, or a process, (...) core service delivery, interpersonal interaction, performance in a wider sense of drama and skill, or the customer's experience of service" [11].

In order to clarify the meanings given to this word, we conducted a literature review that aimed at answering following questions.

Question 1. Which knowledge fields use the term "service"?

Question 2. What is the meaning of service in each of these fields?

The search focused first on the combination of words on title and abstract, and second, full text of selected papers. The initial queries submitted to databases used the keywords: service(s) taxonomy, service(s) management, service(s) concept, service(s) and information technology, and service(s) and information systems. 


\subsection{Concept of Services in Services Marketing}

The well-known definitions of services are historically linked with the services marketing field. The dominant view is that services are opposed to goods. One of the earliest considerations about this matter is presented by Rathmel [12]: “ $\ldots$ to consider a good to be a noun and a service a verb - a good is a thing and a service is an act".

In general, goods are defined as "objects, devices or things", while services are "actions, efforts or performances" [13]. Other definitions are also current and popular. For instance, Lovelock [14], and Zeithaml and Bitner [15] agree in the definition of services as deeds, processes, and performances. A similar definition is contended by Berry [10] that defines services as deeds, acts, or performances. Vargo and Lusch [16] elaborate further, and define services as the "application of specialized competences (knowledge and skills) through deeds, processes, and performance for the benefit of another entity or the entity itself". In the same line, Spohrer and Maglio [4] define services as "clients and providers working together to transform some clientcontrolled state".

The following characteristics of services are commonly used to distinguish them from goods: intangibility, heterogeneity, inseparability, and perishability [17]. These characteristics form the IHIP paradigm, which is a unifying framework that has guided research in the fields of services marketing and OM for the past decades.

However, the boundaries between what are services and goods have become increasingly fuzzy and unclear. Services are often provided through tangible goods and, conversely, goods are applied in the provision of services [18]. Other important aspects, as for example the differences among services and the differences among services firms [17] (rather than the differences between goods and services), have been neglected and are even more poignant today. Thus, there has been an effort to introduce alternative paradigms that can reflect better the present situation.

One example is the services-dominant logic [16] that emphasizes the non-mutual exclusion of goods and services, and "implies that the goal [of marketing] is to customize offerings, to recognize that the consumer is always a co-producer, and to strive to maximize consumer involvement in the customization to better fit his or her needs". Service-dominant logic is argued to constitute the adequate philosophical foundations for SSME [19, 20], and has created large discussion in marketing literature, still not being consensual. A common criticism is the extremism of their conceptualization, with their services-centric view implying that everything (and anything) can be a service.

Other example is the rental/access paradigm proposed by Lovelock and Gummesson [18]. This paradigm builds on the importance of the characteristic of non-transfer of ownership in services emphasizing that, "marketing transactions that do not involve a transfer of ownership are distinctively different from those that do". Thus, services consist of offerings that benefit users through access or temporary possession, having payments of rental or access fees as their counterpart [18]. 


\subsection{The Concept of Services in Operations Management}

Most services involve working together with the customer. Hence, in the area of OM the customer is seen as a basic input for the operations system, with important consequences for the criteria used to evaluate and define services. This characteristic has caused a strong connection between marketing, that creates and manages the expectations of the service to be provided, and operations, that generate the perception of service for customers, thus creating an integrated perspective of services management [21].

In the area of OM, the IHIP paradigm is widely used as the basis for defining services [22]. Spring and Araujo observe that this conception is changing, essentially influenced by the unified service theory (UST), which seems to be the "most radical break with IHIP thinking" in OM [23]. According to this theory, customer inputs, being distinct from customer involvement, are essential for defining services processes.

In services process, the role of customers is different as they "provide significant input" [23]. These inputs are of 3 types: (i) customer self-inputs, (ii) tangible belongings, and (iii) customer-provided information. Customers provide self-inputs either with co-production or when their body is acted upon, as for example with healthcare and transportation services. Sometimes, the customer's tangible belongings are the ones that are acted upon, as for instance reparation services, and other times the customer provides information for the provision of service, as for example fiscal and accounting services [22].

According to Sampson and Froehle [23], UST helps to explain all schemes of classification of services, including the aforementioned IHIP. However, in some cases the rental/access approach [18] to service provision is more helpful as apparently it is more useful to explain the servitization of many manufacturing firms that have "gone downstream", integrating further in the value-chain [24]. Hence, both UST and rental/access approaches are useful alternatives to IHIP classification.

However, the passive conception of customer role, according to the UST, is somewhat limited and does not reflect the contemporary view of customers as coproducers [22]. Moreover, the increasing trend to combine goods and services in offerings, rather than any single of them, and the augmented capabilities of service industries boosted by IT, demand that the field of OM to be directed to the following emergent approach: operations management to operations services through the use of business models that provide added value to customers [22]. This approach expands the OM way of thinking that has traditionally concerned with intra-firm capabilities, namely the control of the flow of materials or information through a sequence of process steps. The integration of the corresponding business models requires that $\mathrm{OM}$ also consider inter-firms capabilities, transactions, revenue models, incentives, and the transfer of provider's capabilities [22].

\subsection{The Concept of Services in Public Administration}

The term "service" is often used in the context of public finance as a result of the state public intervention, to ensure one of its fundamental functions: allocation [25]. This 
function is reflected in the provision of public goods and services [26]. The citizens, in the scrutiny process, ultimately do the choice of public goods and services, and thus legitimate the government decisions reflected in public policies. In Portugal, the implementation of these public goods and services is done with the annual budget, approved by the parliament $[25,27]$.

In administrative science, the term "public service" has two meanings: as functional units, grouped on functional consideration, distinguished according to their purposes (e.g. education services, health services); or as working units, according to a structural perspective depending on the type of activity that is developed (e.g. finance services, administrative services) [27]. This view of the public service may, to some extent, be analyzed from the standpoint of organizational design [28].

Finally, in the scope of public economics, the term "public service" is associated with the function allocation, which will be ensured by the administrative machinery structured according to different models of service management, both from the perspectives of services operations and marketing [29]. Moreover, the result of this function can be the provision of a good or a service to citizens [26]. The state, viewed as the provider of public service through public administration, is thus a service organization [30].

\subsection{The Concept of Services in Software Architectures and Software Development}

Software engineering adopted the concept of service to offer an innovative approach to software development, thus resulting the idea of web services. Services, in this context, are an effective means of building distributed applications, "providing higher-level abstractions for large-scale, open environments" [1]. Thus, services are software components that interact in request-fulfill logic, as opposed to the bureaucratic and conventional logic of command and control.

As a result, software components are articulated with a loose coupling that brings clear benefits to the development and maintenance of software, especially in software distributed over platforms. However, the issues of authentication of client applications and security of data transmission are critical and pose challenges to the development and deployment of services oriented architectures [1].

\subsection{Services in Information Systems and Information Services}

Information systems researchers are positioned at the nexus of organizations and people, where IT helps people's work within organizations. Therefore, they are often concerned with the efficient provision of IT capabilities that helps organizations achieving their goals.

Outsourcing of organizations' IT needs is a growing phenomenon. Researchers in IS are concerned with the effects of outsourcing in organizations and IT projects [31, $32,33]$. It is argued that outsourcing is changing work practices and demanding innovative approaches to management of inter-regional teams. At the same time, 
outsourcing challenges the future of IT job market in developed countries and increases specialization of the workforce [6].

On the other hand, the distribution of information goods is nowadays done via Internet with the rental/access paradigm [18] being the major form of delivery. The intangible nature of information makes it easy to change its form without affecting its content. Thus, the dematerialization of information business (mostly publishing industry) has led to the provision of information as a service. Hence, the term "information services" is often used when referring to the provision of information goods via Internet.

\subsection{Implications of Information Technology to the Conceptualization of Services}

Organizations and businesses are changing, reflecting the impact of IT. Particularly the Internet, known as "one big service vehicle" [34], is altering the way services and goods are delivered and managed, the relations between organizations and customers, and is redefining value chains.

In services, important changes have occurred due to increasing faster communication networks and Internet. Information technology provides significant opportunities for services innovation, superior customer service, and efficiency gains. Moreover, other opportunities such as customers' accessibility and control are also leveraged with self-service technologies (SSTs) [35]. Although technology transforms organization and customers' interaction - shifting from arm's-length relationships to impersonal ones - the customers' expectations of quality are immutable. In fact, customers and employees are not always receptive to technological offers, nor they recognize the associated value [34].

Self-service technologies enable customers to provide their own service and also to take part on the goods acquisition process. The challenges of introducing on-line service technologies are not minor. Often, what works for an organization may not produce the same result in others.

Multi-channel access - the in-person service and the electronic service - is nowadays almost generalized in services sector [36]. Internet-based SSTs and electronic business models created a momentum for services evolve their access strategy, and organizations perceived the increased value of offering services via Internet (e-services). In many cases, e-services are catalyzing service innovation thereby creating competitive advantages. For this reason, benefits of the electronic channel are far beyond providing diverse access options, although in many cases, eservices are indeed a simple expression of multi-channel access [36].

\subsection{Summary}

In this section, we summarize the different conceptualizations of services of the previous sections. In Table 1, we plot the concepts we have previously referred against the areas of management and technology. Thus, the concepts of service more related with the management field (including marketing and operations management) 
are identified. The technology side represents both the fields of software engineering and information systems.

Table 1. The concepts of services in the broad areas of management and technology.

\begin{tabular}{lcc}
\hline & Management & Technology \\
\hline Web services & & $\mathrm{X}$ \\
Self-service technologies & $\mathrm{X}$ & \\
Electronic services & & $\mathrm{X}$ \\
Deeds, processes and performances & $\mathrm{X}$ & \\
Functional units & $\mathrm{X}$ & \\
Working units & $\mathrm{X}$ & \\
IT outsourcing (or IT as a service) & & $\mathrm{X}$ \\
Information services & $\mathrm{X}$ & $\mathrm{X}$ \\
\hline
\end{tabular}

\section{Classifications of Services}

Classifications are instruments that aim at reducing complexity and systematizing knowledge about something. Classification is approachable in two ways: typology and taxonomy. The first one is fundamentally conceptual, whereas the second is essentially empirical [37]. The idea of a typology is that through a combination of variables we can reduce the complexity of a concept, and thereby explain its dimensions [30]. A taxonomy consists on "a scheme that partitions a body of knowledge and defines the relationships among the pieces" [38].

The distinction between these 2 classification approaches is often overlooked in the literature. Several authors refer only to classification schemes, thereby disregarding the dichotomy between taxonomy and typology.

In marketing and management research, typological classifications of services are more abundant. Bowen refers to 16 known typologies for services [39]. He proposes an empirical-based classification scheme based on 7 characteristics that he illustrates by applying it to 10 services business that were representative of 4 different services industries. The characteristics are: (1) importance of employees; (2) customization; (3) ability to switch firms; (4) employee / customer contact; (5) services directed at people or things; (6) continuous benefits; and (7) difference. The objective was to assess if this scheme "would group services from the same industries together or (...) producing groups that would transcend industry boundaries".

Data was collected with a mail survey of consumers, and a review of services marketing literature identified the conceptual classification schemes. After statistical analysis with ANOVA and clustering, services were grouped in 3 clusters: (1) HighContact, Customized, Personal Services, (2) Moderate Contact, Semi-Customized, Non-Personal Services, and (3) Moderate Contact, Standardized Services. 
Since its early beginnings, the field of Services Marketing has sought for a generalizable classification scheme for services. Bowen's empirically based classification work is pioneer in the creation of groups of services based on consumer's perceptions. However, there are some limitations in terms of generalizability because of the number of industries and firms selected and some bias toward upper-lower and middle classes consumers in the sample.

More recently, Lee and Park develop a taxonomy of South-Korean electronic commerce sites [40]. Their objective is to create a taxonomy for online service goods. They identify 11 characteristics of online commercial services, namely (1) criticality for customer, (2) importance of professional knowledge, (3) degree of labor intensity, (4) degree of interaction, (5) degree of customer contact, (6) necessity of membership relation, (7) frequency of purchase, (8) features of search goods, (9) price, (10) degree of customization, and (11) necessity of offline. Forty-five electronic commerce sites were selected for their project. This selection was made through the lists of Korean portal sites and a further refinement with the introduction of the North American Industry Classification System.

Perceptions about the characteristics of services were gathered through a questionnaire to consumers, which had 164 respondents. First, data was statistically analyzed, resulting in six clusters of services: (1) mass, (2) professional, (3) intellectual, (4) credit, (5) support, and (6) facility services [40]. Next, they examine the characteristics of each group and propose marketing and operational strategies for each. Despite the meaningful contributions of this research, the classification is biased and context-sensitive because of the sample used.

The opportunity for an empirically based classification scheme of services is still urgent. The different ways we see the word "services" being used demand a clarification of its meaning in context. The service-dominant logic [16] that SSME has cherished $[41,42]$ further increases this need because that theorization has not yet been empirically validated. Moreover, service innovations depend on interdisciplinary research and skills and, thus, a coherent and comprehensive classification scheme for service scientists and practitioners with different backgrounds is certainly helpful.

\section{Conclusions and Future Work}

This paper focuses on the concept of services from the point of view of marketing, operations management, and the changes introduced in these fields by the widespread use of information technology (IT). Moreover, the appropriation of service's concept in software engineering and the phenomenon of IT-outsourcing, which is increasingly relevant for information systems research, are also explored.

The objective is to clarify the meaning of the concept of service, with the aim of contributing to the literature in the field of service science management and engineering (SSME), based on a transversal perspective. At the end of this exploratory phase, we discuss existing classification schemes and argue that an empirically based classification of services is useful for evolving the field of SSME. As future work, we intend to develop a project with a multidisciplinary team to work on an empirically based taxonomy of services. This project will evolve in two stages. 
The first will clarify which characteristics underlie the different concepts in the areas of study, and the second will identify the differing and approximating characteristics among the different areas.

Acknowledgments. This research was partially supported by Fundação para a Ciência e Tecnologia via Bolsa de Doutoramento SFRH/BD/60838/2009.

\section{References}

1. Huhns, M.H., Singh, M.P.: Service-Oriented Computing: Key Concepts and Principles. IEEE Internet Computing. 9(1), 75--81 (2005)

2. Chesbrough, H., Spohrer, J.: A Research Manifesto for Services Science. Communications of ACM. 49(7), 35--40 (2006)

3. Spohrer, J., Maglio P.P., Bailey, J., Gruhl, D.: Steps Toward a Science of Service Systems. Computer. 40, 71--77 (2007)

4. Spohrer, J., Maglio, P.P.: The Emergence of Service-Science: Towards Systematic Service Innovations to Accelerate Co-Creation of Value. Production \& Operations Management. 17(3), 238--246 (2008)

5. Bitner, M.J., Brown, S.W.: The Service Imperative. Business Horizons. 51(1), 39--46 (2008)

6. Hirschheim, R.A.: Offshoring and the New World Order. Communications of ACM. 52(11), $132--135$ (2009)

7. International Labor Organization: Global Employment Trends. Report, Geneve (2009)

8. International Labor Organization: Global Employment Trends. Report, Geneve (2010)

9. Ostrom, A.S. et al: Moving Forward and Making a Difference: Research Priorities for the Science of Service. Journal of Service Research. 13(1), 4--36 (2010)

10.Berry, L.L.: Services Marketing is Different. Business. 30(3), 24--29 (1980)

11.Johns, N.: What Is This Thing Called Service? European Journal of Marketing. 33(9/10), 958--974 (1999)

12.Rathmel, J.M.: What Is Meant By Services? Journal of Marketing. 30, 32--36 (1966)

13.Hoffman, J.M., Bateson, J.E.: Essentials of Services Marketing. Dryden Press, Forth Worth (1997)

14.Lovelock, C.: Services Marketing, $2^{\text {nd }}$ Edition. Prentice Hall, Englewood Cliffs, NJ (1991)

15.Zeithaml, V., Bitner, M.J.: Services Marketing: Integrating Customer Focus Across The Firm, $2^{\text {nd }}$ Edition. Mc-Graw Hill, Boston (2000)

16.Vargo, S.L., Lusch, R.F.: Evolving to a New Dominant Logic for Marketing. Journal of Marketing. 48(1), 1--17 (2004)

17.Zeithaml, V., Parasuraman, A., Berry, L.L.: Problems and Strategies in Services Marketing. Journal of Marketing. 40, 33--46 (1985)

18.Lovelock, C., Gummesson, E.: Whither Services Marketing? In Search of a New Paradigm and Fresh Perspectives. Journal of Service Research. 17(1), 20--41 (2004)

19.Maglio, P.P., Spohrer, J.: Fundamentals of Service Science. Journal of the Academy of Marketing Science. 36(1), 18--20 (2008)

20.Vargo, S.L., Lusch, R.F.: A Service Logic for Service Science. In: Hefley and Murphy (eds) Service Science, Management and Engineering: Education for the $21^{\text {st }}$ Century, pp. 83--88. Springer, New York (2008)

21.Gianesi, I., Corrêa, H.: Administração Estratégica de Serviços: Operações para a Satisfação do Cliente. Atlas, São Paulo (2000)

22.Spring, M., Araújo, L.: Service, Services, and Products: Rethinking Operations Strategy. International Journal of Operations \& Production Management. 29(5), 444--467 (2009) 
23.Sampson, S.E., Froehle, C.M.: Foundations and Implications of a Proposed Unified Services Theory. Production and Operations Management. 15(2), 329--343 (2006)

24.Wise, R., Baumgartner, P.: Go Dowstream: the New Profit Imperative in Manufacturing. Harvard Business Review. September-October, 133--141 (1999)

25.Pereira, P.T., Afonso, A., Arcanjo, M., Santos, J.: Economia e Finanças Publicas 2.a Edição. Escolar Editora, Lisboa (2007)

26.Musgrave, R.: Public Finance in Theory and Practice $5^{\text {th }}$ Edition. McGraw-Hill, Boston (1989)

27.Amaral, D.F.: Curso de Direito Administrativo Volume 2. Almedina, Coimbra (2002)

28.Andersen, J.A.: Organizational Design: Two Lessons to Learn Before Reorganizing. International Journal of Organizations Theory and Behavior. 5(3,4) 343--358 (2002)

29.Osborne, S.: Delivering Public Service: Time for a New Theory? Public Management Review. 12(1), 1--10 (2010)

30.Mills, P.K., Margulies, N.: Toward a Core Typology of Service Organizations. The Academy of Management Review. 5(2), 255--265 (1980)

31.Choudhury, V., Sabherwal, R.: Portfolios of Control in Outsourced Software Development Projects. Information Systems Research. 14(3), 291--314 (2003)

32.Levina, N.: Collaborating on Multiparty Information Systems Development Projects: A Collective Reflection-in-Action View. Information Systems Research. 16(2), 109--130 (2005)

33.Sarker, S., Sarker, S.: Exploring Agility in Distributed Information Systems Developmente Teams: an Interpretive Study in an Offshoring Contexr. Information Systems Research. 20(3), 440--461 (2009)

34.Bitner, M.J.: Service and Technology: Opportunities and Paradoxes. Managing Service Quality. 11(6), 375--379 (2001)

35. Pujari, D.: Self-service with a Smile? Self-Service Technology Encounters Among Canadian Business-to-Business. International Journal of Service Industry Management. 15(2), 200--219 (2004)

36.Rowley, J.: An Analysis of the E-Service Literature: Towards a Research Agenda. Internet Research. 16(3), 330--359 (2006)

37.Bailey, K.D.: Typologies and Taxonomies: an Introduction to Classification Techniques. Sage Publications (1994)

38.IEEE, IEEE Standars Taxonomy for Software Engineering Standards. IEEE, New York (1989)

39.Bowen, J.: Development of a Taxonomy of Services to Gain Strategic Marketing Insights. Journal of the Academy of Marketing Science. 18(1), 43--49 (1990)

40. Lee, S., Park, Y.:The Classification And Strategic Management of Services in ECommerce: Development of Service Taxonomy Based on Customer Perception. Expert Systems With Applications. 36, 9618--9624 (2009)

41.Spohrer, J., Vargo, S.L., Caswell, N., Maglio, P.P.: The Service System is the Basic Abstraction of Service Science. In: Proceedings of the $41^{\text {st }}$ Annual Hawaii International Conference on System Sciences. (2008)

42. Vargo, S.L., Akaka, M.: Service-Dominant Logic as a Foundation for Service Clarifications. Service Science. 1(1), 32--41 (2009) 